Article

\title{
Estimating Canopy Characteristics of Inner Mongolia's Grasslands from Field Spectrometry
}

\author{
Feng Zhang ${ }^{1}$, Ranjeet John ${ }^{2}$, Guangsheng Zhou ${ }^{1,3, *}$, Changliang Shao ${ }^{1}$ and Jiquan Chen ${ }^{2,4}$ \\ 1 State Key Laboratory of Vegetation and Environmental Change, Institute of Botany, \\ Chinese Academy of Sciences, Beijing 100093, China; E-Mails: zhangfeng@ibcas.ac.cn (F.Z.); \\ zkyscl@ibcas.ac.cn (C.S.) \\ 2 Department of Environmental Sciences, University of Toledo, Toledo, OH 43606, USA; \\ E-Mails: ranjeet.john@utoledo.edu (R.J.); jiquan.chen@utoledo.edu (J.C.) \\ 3 Chinese Academy of Meteorological Sciences, Beijing 100081, China \\ 4 International Center for Ecology, Meteorology and Environment, School of Applied Meteorology, \\ Nanjing University of Information Science and Technology, Nanjing 210044, China \\ * Author to whom correspondence should be addressed; E-Mail: gszhou@ibcas.ac.cn; \\ Tel.: +86-10-6283-6268; Fax: +86-10-8259-5962.
}

Received: 2 January 2014; in revised form: 26 February 2014 / Accepted: 3 March 2014 / Published: 12 March 2014

\begin{abstract}
This study was designed to estimate the canopy biophysical characteristics of semi-arid grassland ecosystems by using in situ field spectrometry measurements to identify important spectral information for predictions at broader spatial scales. Spectral vegetation indices (VIs), reflectance spectra, continuum removal spectra, and the amplitude of the red edge peak $\left(\mathrm{dr}_{\mathrm{re}}\right)$ based on 61 well-replicated field measurements across a large area in Inner Mongolia were used to develop empirical models for estimating four key canopy biophysical features: percent green coverage $(P G C)$, canopy height $(H)$, green aboveground biomass $(G B M)$, and total aboveground biomass $(T B M)$. The results showed that NDVI, EVI, NDSVI, and LSWI were useful for estimating canopy biophysical features, with NDSVI being the most significant variable. The $P G C$ was accurately estimated with spectral reflectance at $441 \mathrm{~nm}$ and $2220 \mathrm{~nm}\left(\mathrm{R}^{2}=0.71\right)$, while the maximum depth of band $\left(D_{c}\right)$, absorption area $\left(D_{\text {area }}\right)$ in the red domain and $\mathrm{dr}_{\mathrm{re}}$ were selected for estimating $T B M$ and $G B M\left(\mathrm{R}^{2}=0.51\right.$ and 0.44$)$. Among the four canopy features, $P G C$ received the highest confidence from all of the models $\left(\mathrm{R}^{2}=0.81\right)$, while $H$ was the most difficult to estimate $\left(\mathrm{R}^{2}=0.49\right)$. Finally, the degree of disturbances and ecosystem types appeared to be a significant variable for model development.
\end{abstract}


Keywords: continuum removal spectra; hyperspectral field spectroscopy; reflectance spectra; vegetation indices; vegetation biophysical characteristics

\section{Introduction}

Accurate quantification of vegetation canopy characteristics has been a research focus for its crucial role in ecosystem studies on productivity, carbon cycles, nutrient allocation, and biological diversity [1-3]. Despite previous efforts to quantify canopy biophysical properties using various methods at multiple spatial scales, the task remains challenging [3]. Remote sensing technology, meanwhile, viewed as a time- and cost-efficient approach among the most promising methods, allows scientists to proceed with large-scale monitoring of ecological properties at broader scales [4,5] and has been widely used to estimate the biophysical characteristics of different vegetation types on landscape and regional scales. However, only a limited number of applications of hyperspectral field spectroscopy data have been promoted due to their capability of quantifying land surface properties, such as canopy cover, height, leaf area index (LAI), etc.

Hyperspectral scanners consisting of individual channels with high spectral resolution at $10 \mathrm{~nm}$ and 400-2500 $\mathrm{nm}$ spans have the potential to significantly improve our ability to discriminate between the characteristics of spectral features for analysis, classification, and monitoring of canopy properties [6,7]. Different vegetation types have distinct pigment concentrations, leaf characteristics, and canopy structures, indicating the existence of unique spectral properties of absorption and reflectance for each species or vegetation type [7-10]. Clearly, narrow bands of hyperspectral remote sensing are more useful than broad bands in the quantification of vegetative biophysical variables; in particular, the red portion of the electromagnetic spectrum might provide more stable information on canopy attributes [11].

Hyperspectral studies have been widely conducted in laboratories, aiming toward their ultimate use in actual fields. Several challenges remain for their effective use. First, canopy reflectance in the field is complex for its similarity of biochemical composition among species, overlapping of their absorption features for biochemical constituents in live vegetation [7], high atmospheric absorption interruption [12-14], and variation of vegetation canopy water content caused by incident precipitation that is particularly vital in semi-arid vegetation [12]. Secondly, there is no consensus about the relationship between canopy properties and the reflectance that can be used to scale up to the entire canopy because each measure within the sensor view angle includes variable vegetation, mosaics of the soil background, and other non-photosynthetically active vegetation $[5,12,15,16]$. Finally, spectral variations may also occur for the same species under different conditions of age, microclimate, soil characteristics, precipitation, topography, phenology, and stressors [17-22]. Clearly, substantial and extensive in situ spectral data are needed to promote the uses of hyperspectral reflectance from a remote sensing perspective before it can be linked with satellite data for applications at broader temporal and spatial scales [14,23].

Here, an intensive field campaign was conducted to explore the usefulness of in situ hyperspectral data across a large area of semi-arid landscape in Inner Mongolia, China. Grasslands are the most 
dominant ecosystems on the Mongolian Plateau [24] and the most important natural resources for its large livestock population and economic development. Grassland degradation in recent years has occurred due to increasing climate extremes (e.g., cold winter) [25] and growing human pressures [26]. Therefore, accurate monitoring and estimating canopy biophysical features of grasslands by using high-resolution spectral measurements becomes an urgent demand.

In this study, our objectives were set to: (1) investigate the potential uses of field spectrometry in estimating the biophysical characteristics of different grassland types with different human disturbances across a large spatial area in the arid and semi-arid areas of Inner Mongolia; (2) depict the sensitive spectral properties and any quantitative measures generated from these spectral properties that can be used to estimate biophysical characteristics by developing empirical models; and (3) develop empirical models by identifying significant remote sensing signals to estimate community functions such as biomass.

\section{Methods}

\subsection{Study Area}

The study area was located between $38.28^{\circ}-46.60^{\circ} \mathrm{N}$ and $107.65^{\circ}-118.12^{\circ} \mathrm{E}$ in Inner Mongolia, China (Figure 1). The region is characterized by an arid and semi-arid continental climate with a strong climate gradient and various land use practices. The annual precipitation ranges from $150 \mathrm{~mm}$ to $400 \mathrm{~mm}$ and the dominant vegetation types include a typical steppe and a desert steppe [27], both under intensive human disturbances. Among the 61 sampling sites, 28 were measured in 2006 and 33 were measured in 2007. Considering the variations in grassland types and human activities, 11 sites were recorded as having "low human disturbance" for the typical steppes (i.e., Class I) and 24 sites as having "intermediate human disturbance" (i.e., Class II). The remaining 26 sites were in the desert steppe and assigned as Class III. The typical steppe has an annual precipitation of 250-400 mm, annual accumulated temperature of $2600-2800{ }^{\circ} \mathrm{C}$, and is dominated by Stipa krylovii, Leymus chinensis, Cleistogenes squarrosa, Koeleria cristata, Artemisia spp., and Potentilla spp., while the desert steppe has an annual precipitation of $150-250 \mathrm{~mm}$, annual accumulated temperature of $2200-2500{ }^{\circ} \mathrm{C}$, and is dominated by Stipa klemenvii, S. breviflora, and S. glareosa [27].

\subsection{Field Spectral Measurement}

Field reflectance spectra measurements were conducted from 11 July to 25 August 2006 and 25 June to 24 July 2007. All spectral measurements were taken between $10.5 \mathrm{~h}$ and $14.5 \mathrm{~h}$ on clear and sunny days. A GER3700 (Geophysical and Environmental Research Corporation, Buffalo, NY, USA) spectroradiometer was used for taking in situ spectral data. The GER 3700 is a three-dispersion grating spectroradiometer using $\mathrm{Si}$ and $\mathrm{PbS}$ detectors with a single field of view of $25^{\circ}$. It has 647 wave bands and a wavelength range of 350-2500 nm with sampling intervals of $1.5 \mathrm{~nm}$ in the $350-1050 \mathrm{~nm}, 6.2 \mathrm{~nm}$ in the $1050-1900 \mathrm{~nm}$, and $9.5 \mathrm{~nm}$ in the $1900-2500 \mathrm{~nm}$. The spectral resolution is $3 \mathrm{~nm}$ over the range of 300-1050 nm, $11 \mathrm{~nm}$ over the range of 1050-1900 nm, and $16 \mathrm{~nm}$ over the range of 1900-2500 nm. The sensor was hand-held approximately one meter above the ground at the nadir position. Three replicates were conducted at each plot and five samplings (north, south, east, west, and 
center positions) were conducted in each of the 61 sites within a $250 \mathrm{~m} \times 250 \mathrm{~m}$ area. Altogether, we had 915 measurements in 2006 and 2007.

Figure 1. Spatial locations of 61 sampling sites in the study area overlaid on land cover types in Inner Mongolia, China. The land cover types were from the 1:4,000,000 Vegetation Atlas of China compiled by the Editorial Board of Vegetation Maps of China, 2001.

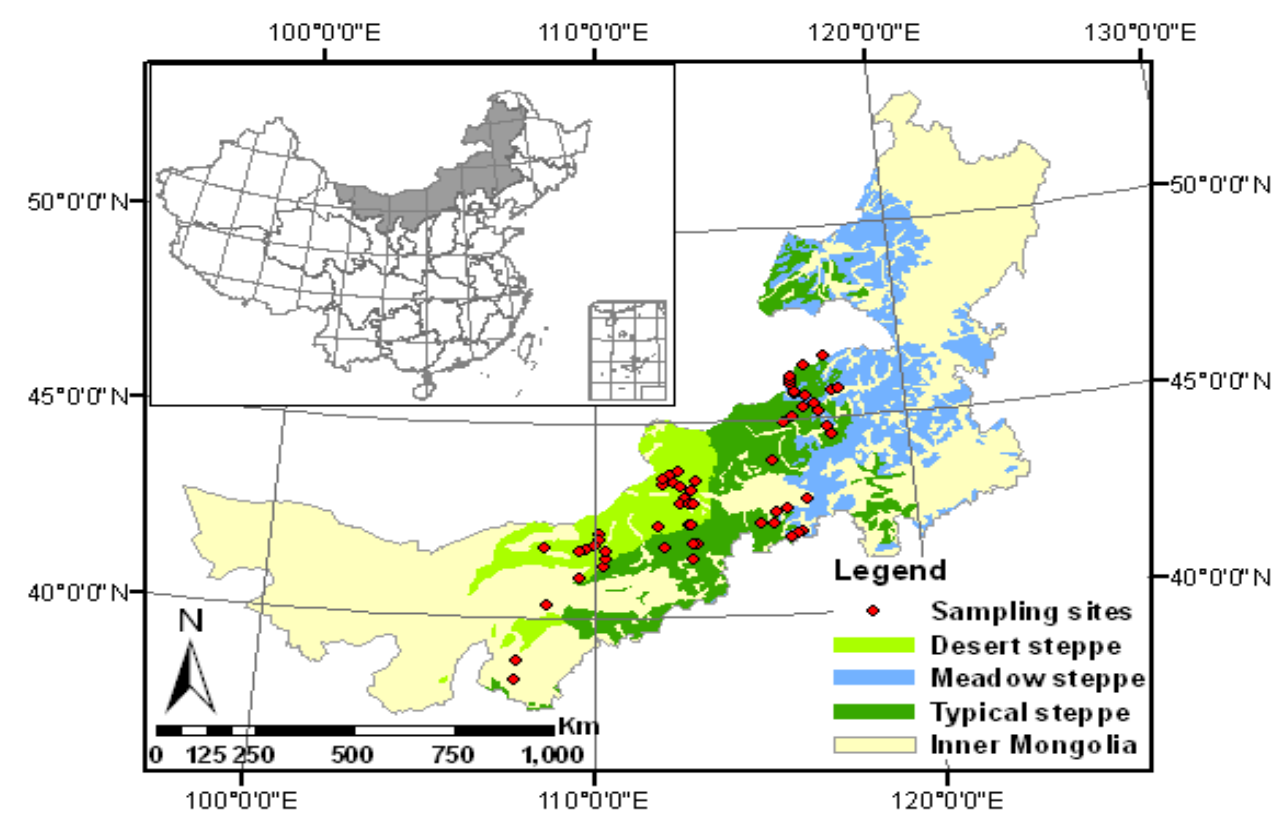

\subsection{Vegetation Sampling}

After taking a spectral measurement, percent green cover $(P G C, \%)$, canopy height $(H, \mathrm{~cm})$, green aboveground biomass $\left(G B M, \mathrm{~g} \cdot \mathrm{m}^{-2}\right)$, and total aboveground biomass $\left(T B M, \mathrm{~g} \cdot \mathrm{m}^{-2}\right)$ were measured or harvested using three $50 \mathrm{~cm} \times 50 \mathrm{~cm}$ plots. $P G C$ is the percentage of the ground area that is covered by green leaves and measured through visual estimations. The harvested green plants and non-green plants were oven-dried at $65{ }^{\circ} \mathrm{C}$ for $48 \mathrm{~h}$ and then weighed for green aboveground biomass $(G B M)$ and total (green plus non-green) aboveground biomass (TBM).

\subsection{Data Analysis}

A moving Savitzky-Golay filter [28] with a frame size of 15 (second-degree polynomial) was applied to the averaged reflectance spectra to eliminate noise from the sensor using MATLAB 2007. Moreover, the reflectance of the following wavelengths was excluded due to high levels of noise or atmospheric water vapor absorption: $<400 \mathrm{~nm},>2400 \mathrm{~nm}, 1350-1590 \mathrm{~nm}$, and 1780-1970 nm [7,12]. Ultimately, 517 valid wavebands were obtained from each spectrum.

We first calculated the following quantitative metrics that are widely used in remote sensing studies: normalized difference vegetation index (NDVI): NDVI $=\left(R_{\text {nir }}-R_{\text {red }}\right) /\left(R_{\text {nir }}+R_{\text {red }}\right)$ [29]; enhanced vegetation index (EVI): EVI $=2.5 \times\left(R_{\text {nir }}-R_{\text {red }}\right) /\left(R_{\text {nir }}+6 \times R_{\text {red }}-7.5 \times R_{\text {blue }}+1.0\right)$ [30]; normalized difference senescence vegetation index (NDSVI): NDSVI $=\left(R_{\text {swir }}-R_{\text {red }}\right) /\left(R_{\text {swir }}+R_{\text {red }}\right)[31]$; and land surface water index (LSWI): LSWI $=\left(R_{\text {nir }}-R_{\text {swir }}\right) /\left(R_{\text {nir }}+R_{\text {swir }}\right)[32,33]$, where $R_{\text {nir }}, R_{\text {red }}, R_{\text {blue }}$, and $R_{\text {swir }}$ are the averaged reflectance among the waveband range to match MODIS data in the 
near-infrared (841-876 nm), red (620-670 nm), blue (459-479 $\mathrm{nm})$, and shortwave infrared (SWIR1: 1628-1652 nm) wavelengths, respectively.

The amplitude of the red edge peak $\left(\mathrm{dr}_{\mathrm{re}}\right)$ was determined as the maximum first derivative of the reflectance between 680 and $750 \mathrm{~nm}$ [34]. The continuum removal analysis, a way of normalizing the reflectance spectra, was applied for the absorption features from $550 \mathrm{~nm}$ to $750 \mathrm{~nm}$ in the visible domain, the maximum band depth $\left(D_{c}\right)$, the area under the curve $\left(D_{\text {area }}\right)$, and the normalization of $D_{c}$ by the absorption feature $\left(D_{c} / D_{\text {area }}\right)$ were calculated as follows: the $D_{c}$ was the maximum band depth (BD) at the band center. The BD was calculated by subtracting the continuum-removed reflectance at a certain wavelength from 1 and, thus, the value of the BD is between zero and one. The continuum-removed reflectance is obtained by dividing the reflectance value for each waveband in the absorption feature by the reflectance level of the continuum line at the corresponding wavelength. The $\mathrm{D}_{\text {area }}$ was calculated as the integration of the BD over the spectral interval of interest. The $\mathrm{D}_{\mathrm{c}} / \mathrm{D}_{\text {area }}$ was calculated by dividing the $\mathrm{D}_{\mathrm{c}}$ by $\mathrm{D}_{\text {area }}$, i.e., the normalization of the $\mathrm{D}_{\mathrm{c}}$ by the absorption feature [35-37].

\subsection{Statistical Analysis}

Radiative transfer models, being functions of canopy, leaf, and soil background characteristics, had theoretically physical foundations. However, they had the ill-posed nature of model inversion [38]. Statistical approaches, being sensor-specific and dependent on site and sampling conditions, but easy to implement, were used in this study. Descriptive statistics and univariate and multivariate analyses were applied to initially explore the statistical properties of each dataset. Although, the "full spectrum" methods, such as partial least squares regression, had better predictive powers for biophysical variables [39]. Here, a stepwise linear regression, which can establish a minimum set of wavelengths and permit an optimum modeling of the target variable, was used to select wavelengths from spectral property variables. To ensure the normality of residuals and to improve the statistical models, vegetation parameters were transformed by natural logarithmic and square root arithmetic and a general linear model was used to examine the effects of class variables on the grass canopy properties (SAS 9.1 TS level XP-PRO platform). In this model, spectral information and the class variable were set as the independent variables, while canopy characteristics were set as the dependent variables.

\section{Results}

\subsection{Variation in the Canopy Properties and Reflectance Spectrum}

The canopy characteristics among the sampled grasslands were highly variable (Table 1). PGC ranged from $3.0 \%$ to $78.8 \%$ with an average (standard deviation or SD) of $28.0(21.77) \%$, $H$ ranged from $4.3 \mathrm{~cm}$ to $45.0 \mathrm{~cm}$ with an average (SD) of $19.1(10.69) \mathrm{cm}, G B M$ from $4.8 \mathrm{~g} \cdot \mathrm{m}^{-2}$ to $336.4 \mathrm{~g} \cdot \mathrm{m}^{-2}$ with an average (SD) of $72.6(72.23) \mathrm{g} \cdot \mathrm{m}^{-2}$, and $T B M$ from $7.6 \mathrm{~g} \cdot \mathrm{m}^{-2}$ to $362.7 \mathrm{~g} \cdot \mathrm{m}^{-2}$ with an average (SD) of $91.5(88.18) \mathrm{g} \cdot \mathrm{m}^{-2}$. The Class I steppe, which experienced relatively fewer human disturbances, had the highest $P G C$ with an average (SD) of 56.1(16.01) \%, the highest average (SD) $H$ of 27.5(9.07) $\mathrm{cm}, G B M$ of $150.4(69.95) \mathrm{g} \cdot \mathrm{m}^{-2}$, and $T B M$ of 212.4(84.53) $\mathrm{g} \cdot \mathrm{m}^{-2}$. Class III in the desert steppe had the lowest average (SD) canopy cover of 11.6(7.28), and relatively lower $H$ of $17.4(10.45) \mathrm{cm}, G B M$ of $58.7(81.29) \mathrm{g} \cdot \mathrm{m}^{-2}$, and $T B M$ of $65.6(83.68) \mathrm{g} \cdot \mathrm{m}^{-2}$. 
Vegetation reflectance based on spectral measurements also showed a considerable difference between the two years and among the three vegetation classes (Figure 2). The reflectance spectra in 2007 were higher than those in 2006 in visible and near-infrared regions, excluding shortwave infrared regions. Class III, mostly in the desert steppe with short and sparse vegetation, had higher reflectance in the visible and near-infrared domains than Class I and Class II in typical steppes (Figure 2). Additionally, there were noticeable spectral differences between Class I and Class II for their different disturbance degrees, especially in the visible region. The reflectance in the second shortwave infrared domain (1900-2450 nm) of Class II was higher than that of Class I, which was higher than that of Class III. This pattern corresponded well to the canopy development conditions (Table 1). The visible region captures the changes of chlorophyll absorption, the near-infrared region reflects optical properties of leaves, the first shortwave infrared region $(1500-1900 \mathrm{~nm})$ is related to leaf biochemical characteristics, and the second shortwave infrared bands for the development of cellulose and lignin as a plant ages.

Table 1. Summary statistics of the biophysical characteristics from 61 sampled communities in Inner Mongolia.

\begin{tabular}{cccccc}
\hline & Min & Mean & Max & SD & Coefficient of Variation \\
\hline \multicolumn{5}{c}{ The whole study area $(n=61)$} \\
\hline$P G C(\%)$ & 3.0 & 28.0 & 78.8 & 21.77 & 0.78 \\
$H(\mathrm{~cm})$ & 4.3 & 19.1 & 45.0 & 10.69 & 0.56 \\
$G B M\left(\mathrm{~g} \cdot \mathrm{m}^{-2}\right)$ & 4.8 & 72.6 & 336.4 & 72.23 & 1.00 \\
$T B M\left(\mathrm{~g} \cdot \mathrm{m}^{-2}\right)$ & 7.6 & 91.5 & 362.7 & 88.18 & 0.96 \\
\hline \multicolumn{5}{c}{ Class I: less disturbances in typical steppe $(n=11)$} \\
\hline$P G C(\%)$ & 28.3 & 56.1 & 78.8 & 16.01 & 0.29 \\
$H(\mathrm{~cm})$ & 13.7 & 27.5 & 41.7 & 9.07 & 0.33 \\
$G B M\left(\mathrm{~g} \cdot \mathrm{m}^{-2}\right)$ & 70.6 & 150.4 & 302.9 & 69.95 & 0.47 \\
$T B M\left(\mathrm{~g} \cdot \mathrm{m}^{-2}\right)$ & 127.4 & 212.4 & 362.7 & 84.53 & 0.40 \\
\hline \multicolumn{7}{c}{ Class II: more disturbances in typical steppe $(n=24)$} \\
\hline$P G C(\%)$ & 5.0 & 32.9 & 75.0 & 18.96 & 0.58 \\
$H(\mathrm{~cm})$ & 4.3 & 17.0 & 39.7 & 10.10 & 0.59 \\
$G B M\left(\mathrm{~g} \cdot \mathrm{m}^{-2}\right)$ & 12.4 & 51.3 & 142.0 & 28.02 & 0.55 \\
$T B M\left(\mathrm{~g} \cdot \mathrm{m}^{-2}\right)$ & 13.9 & 63.1 & 142.0 & 31.25 & 0.50 \\
\hline \multicolumn{5}{c}{ Class III: desert steppe $(n=26)$} \\
\hline$P G C(\%)$ & 3.0 & 11.6 & 41.7 & 7.28 & 0.63 \\
$H(\mathrm{~cm})$ & 5.0 & 17.4 & 45.0 & 10.45 & 0.60 \\
$G B M\left(\mathrm{~g} \cdot \mathrm{m}^{-2}\right)$ & 4.8 & 58.7 & 336.4 & 81.29 & 1.39 \\
$T B M\left(\mathrm{~g} \cdot \mathrm{m}^{-2}\right)$ & 7.6 & 65.6 & 360.0 & 83.68 & 1.28 \\
\hline
\end{tabular}

\subsection{Estimations from VIs}

Among the four vegetation indices, NDSVI and EVI were selected as the significant independent variables through stepwise regression for estimating transformed $P G C\left(\mathrm{R}^{2}=0.64 ; p<0.001\right)$, while NDSVI alone was selected to estimate transformed $G B M$ and $T B M\left(\mathrm{R}^{2}=0.24,0.32\right.$ and $p<0.001$, 0.001 , respectively). The transformed $H$ was linearly correlated with NDVI $\left(\mathrm{R}^{2}=0.40\right)$, while NDSVI correlated well with transformed $G B M$ and $T B M$, with $\mathrm{R}^{2}$ of 0.24 and 0.32 , respectively (Figure 3). 
Figure 2. Changes in spectral reflectance of (a) 2006 and 2007; and (b) Class I, Class II, and Class III in Inner Mongolia.

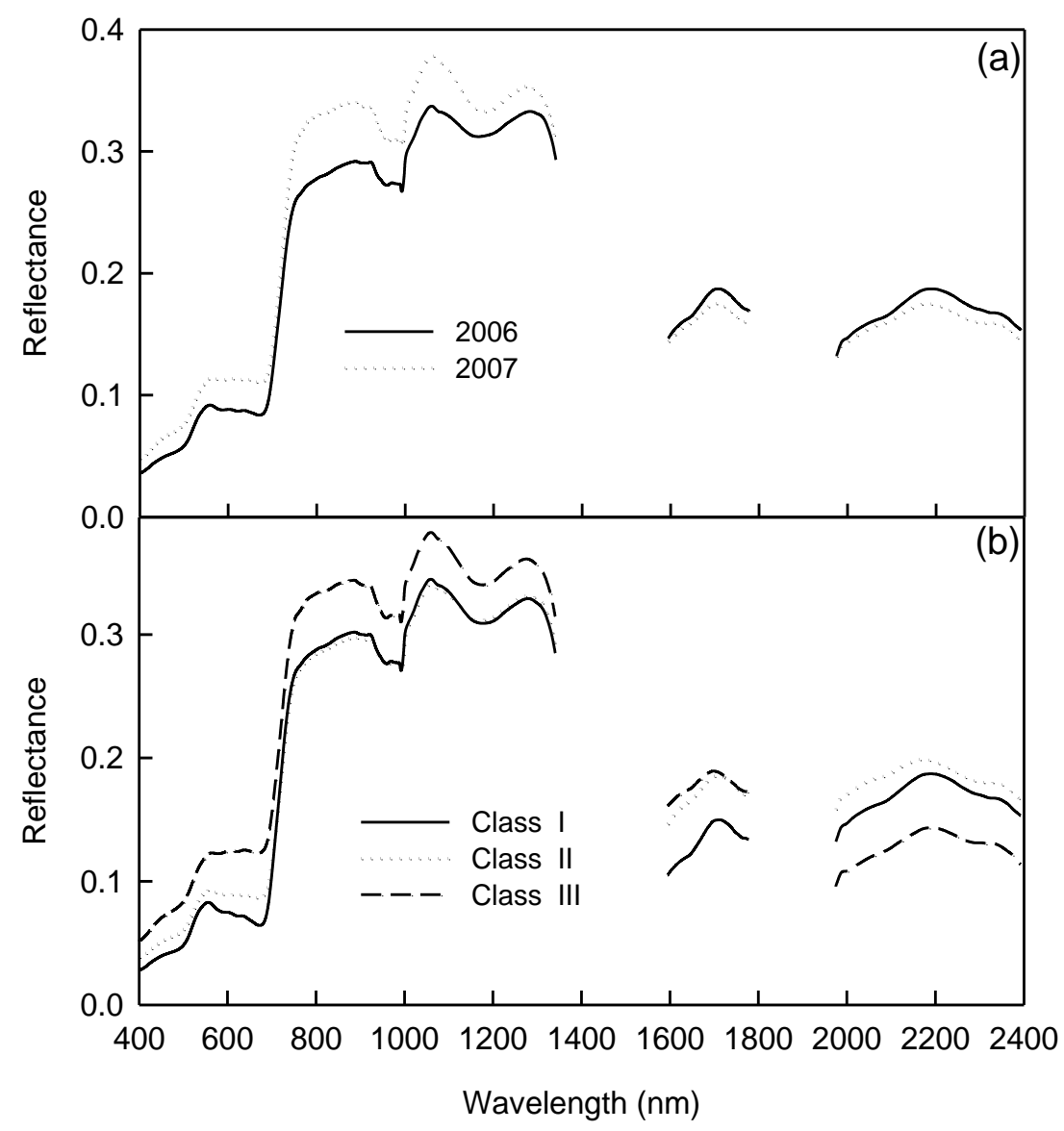

Figure 3. The relationships between transformed canopy features and selected spectral drivers for (a) $P G C(\%)$; (b) $H(\mathrm{~cm})$; (c) $G B M\left(\mathrm{~g} \cdot \mathrm{m}^{-2}\right)$; and (d) $T B M\left(\mathrm{~g} \cdot \mathrm{m}^{-2}\right)$ in Inner Mongolia. The driving factors were selected with stepwise linear regression with $p<0.05$.

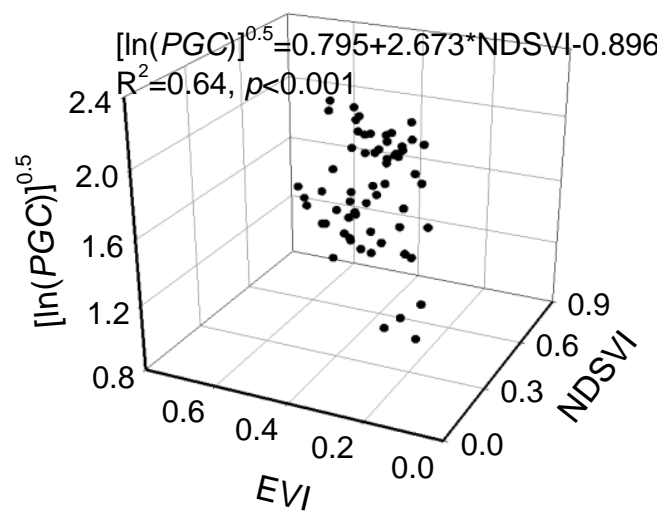

(a)

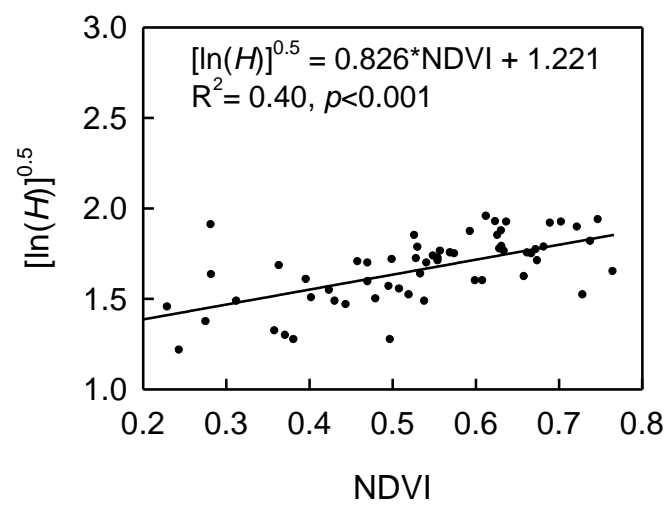

(b) 
Figure 3. Cont.

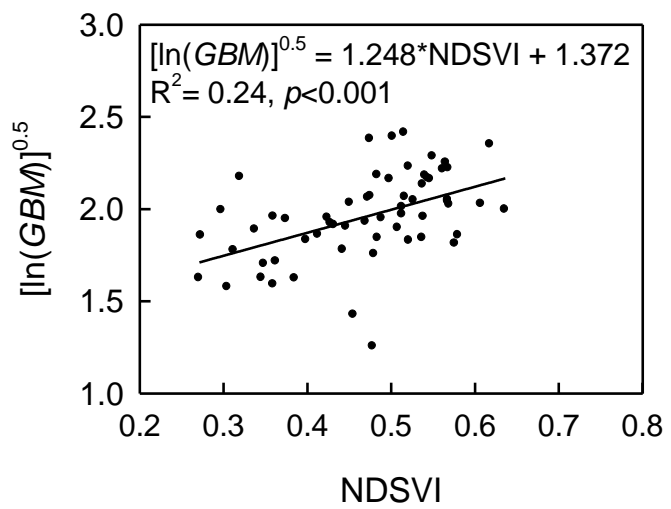

(c)

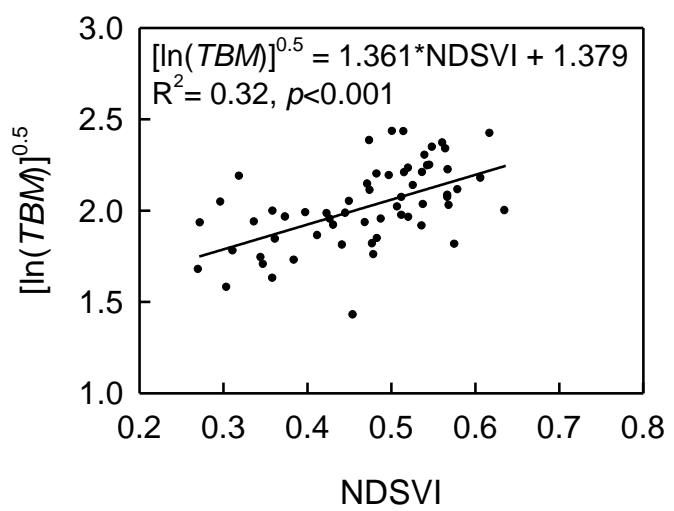

(d)

\subsection{Estimations from Reflectance Spectra}

Using the Pearson product moment correlation function for all wavelengths of spectral measurements, we identified several spectra that had high correlations with canopy biophysical properties (Figure 4), including reflectance at $421 \mathrm{~nm}, 441 \mathrm{~nm}, 676 \mathrm{~nm}, 723 \mathrm{~nm}, 993 \mathrm{~nm}, 1210 \mathrm{~nm}, 1640 \mathrm{~nm}$, and $2220 \mathrm{~nm}$. These spectra were consequently selected to explore their roles in estimating $P G C, H, G B M$, and $T B M$ (Figure 5) through stepwise regression. $P G C$ could be estimated from spectra in visible (400-700 nm) and part-infrared (700-1200 nm) regions. Our confidence level for estimating transformed $H, G B M$, and TBM varied from 39\% to 44\% (Figure 5). Overall, it seemed that the canopy characteristics, except for $H$, could be more confidently estimated by reflectance spectra than by using VIs. Reflectance at 441 $\mathrm{nm}$ and $2220 \mathrm{~nm}$ explained $71 \%$ of the transformed PGC (Figure 5).

\subsection{Estimations from Continuum-Removal Spectra and $d r_{r e}$}

The predictive powers of canopy characteristics by continuum removal spectra and $\mathrm{dr}_{\mathrm{re}}$ were further improved for $G B M$ and $T B M$ (Table 2), with $\mathrm{R}^{2}$ values for transformed $P G C, H, G B M$, and $T B M$ that varied from 0.43 to 0.54 .

Figure 4. Variations of correlation coefficients of determination $\left(\mathrm{R}^{2}\right)$ with wavelength, showing the important wavelengths needed for estimating $P G C(\%), H(\mathrm{~cm}), G B M\left(\mathrm{~g} \cdot \mathrm{m}^{-2}\right)$, and $T B M\left(\mathrm{~g} \cdot \mathrm{m}^{-2}\right)$ in Inner Mongolia.

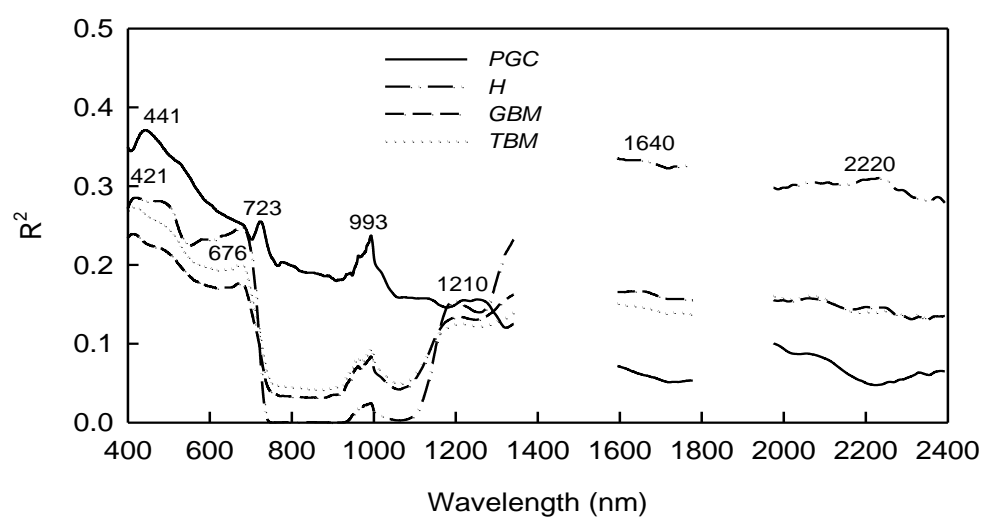


Figure 5. The empirical relationships between transformed (a) $P G C(\%)$; (b) $H(\mathrm{~cm})$; (c) $G B M\left(\mathrm{~g} \cdot \mathrm{m}^{-2}\right)$; and (d) $T B M\left(\mathrm{~g} \cdot \mathrm{m}^{-2}\right)$ and canopy reflectance in Inner Mongolia. The significant driving variables were selected with stepwise linear regression with $p<0.05$.

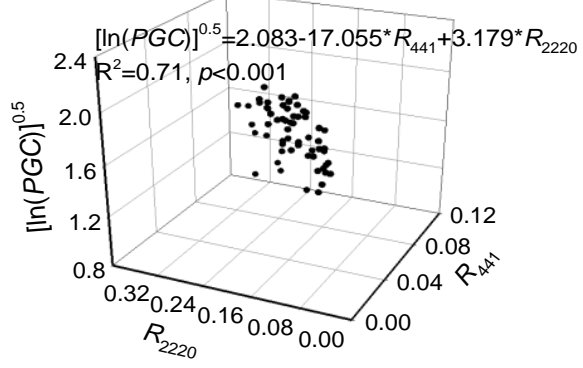

(a)

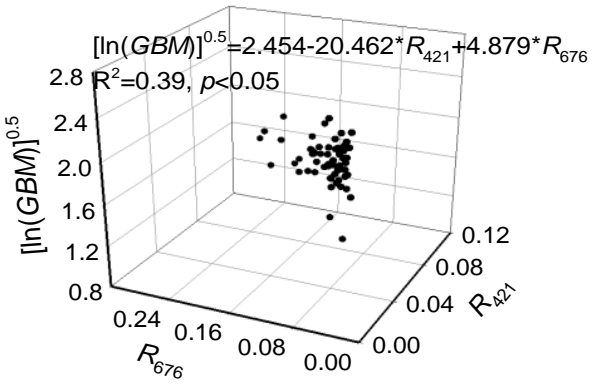

(c)

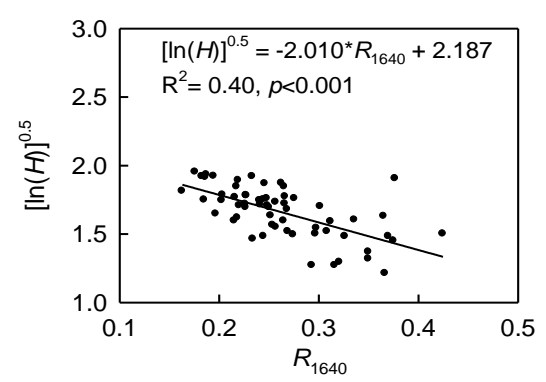

(b)

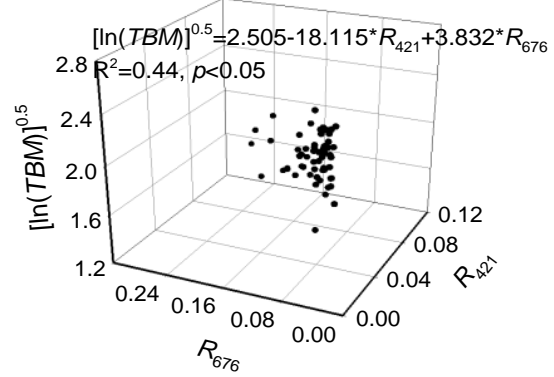

(d)

Table 2. Empirical models and performances from stepwise regressions using continuum-removed spectra and $\mathrm{dr}_{\mathrm{re}}$ to estimate canopy properties $(n=61)$.

\begin{tabular}{ccccc}
\hline & Spectra1 & Spectra2 & Spectra3 & $\mathbf{R}^{\mathbf{2}}$ \\
\hline$P G C$ & $\mathrm{D}_{\mathrm{c}}$ & $\mathrm{dr}_{\mathrm{re}}$ & $\mathrm{D}_{\text {area }}$ & 0.41 \\
$H$ & $\mathrm{D}_{\mathrm{c}}$ & - & - & 0.30 \\
$G B M$ & $\mathrm{D}_{\mathrm{c}}$ & $\mathrm{dr}_{\mathrm{re}}$ & $\mathrm{D}_{\text {area }}$ & 0.27 \\
$T B M$ & $\mathrm{D}_{\mathrm{c}}$ & $\mathrm{dr}_{\mathrm{re}}$ & $\mathrm{D}_{\text {area }}$ & 0.31 \\
{$[\ln (P G C)]^{0.5}$} & $\mathrm{D}_{\mathrm{c}}$ & $\mathrm{dr}_{\mathrm{re}}$ & $\mathrm{D}_{\text {area }}$ & 0.54 \\
{$[\ln (H)]^{0.5}$} & $\mathrm{D}_{\mathrm{c}}$ & $\mathrm{D}_{\mathrm{c}} / \mathrm{D}_{\text {area }}$ & - & 0.43 \\
{$[\ln (G B M)]^{0.5}$} & $\mathrm{D}_{\mathrm{c}}$ & $\mathrm{dr}_{\text {re }}$ & $\mathrm{D}_{\text {area }}$ & 0.44 \\
{$[\ln (T B M)]^{0.5}$} & $\mathrm{D}_{\mathrm{c}}$ & $\mathrm{dr}_{\mathrm{re}}$ & $\mathrm{D}_{\text {area }}$ & 0.51 \\
\hline
\end{tabular}

\subsection{Estimations Using All Independent Variables}

Using all of the independent variables, including VIs, reflectance spectra, continuum removal spectra, and $\mathrm{dr}_{\mathrm{re}}$ variables, the predictive powers for canopy characteristics were further improved (Table 3 ). The $\mathrm{R}^{2}$ value for transformed $P G C$ from $\mathrm{dr}_{\mathrm{re}}$, reflectance at $441 \mathrm{~nm}$ and $1210 \mathrm{~nm}$ was 0.72 , while it was 0.55 for transformed $G B M$ from $\mathrm{dr}_{\mathrm{re}}$, NDVI, reflectance at $421 \mathrm{~nm}$ and $723 \mathrm{~nm}$, and 0.57 for $T B M$ from $\mathrm{dr}_{\mathrm{re}}$, reflectance at $723 \mathrm{~nm}$ and NDVI. However, the $\mathrm{R}^{2}$ value for transformed $H$ remained around 0.40 .

\subsection{Estimations by Disturbances and Ecosystem Type}

Disturbance intensity played a significant role in the development of our empirical models for estimating canopy features (Table 4). The $\mathrm{R}^{2}$ value for estimating transformed $P G C$ increased 
from 0.71 to 0.81 when disturbance intensity and grassland type were included as category variables in our linear models (Figure 5, Table 4). More importantly, inclusion of class variable in our model development reduced the number of drivers, while $\mathrm{R}^{2}$ increased from 0.51 to 0.63 for $T B M$, from 0.44 to 0.59 for $G B M$, and from 0.40 to 0.49 for $H$ (Tables 2 and 4, Figure 5).

Table 3. Empirical models and performances of stepwise regressions based on vegetation indices (VIs), reflectance spectra, continuum removal spectra, and $\mathrm{dr}_{\mathrm{re}}(n=61)$.

\begin{tabular}{cccccc}
\hline & Spectra1 & Spectra2 & Spectra3 & Spectra4 & $\mathbf{R}^{2}$ \\
\hline$P G C$ & NDSVI & EVI & - & - & 0.55 \\
$H$ & $1640 \mathrm{~nm}$ & - & - & - & 0.33 \\
$G B M$ & $421 \mathrm{~nm}$ & - & - & - & 0.24 \\
$T B M$ & $421 \mathrm{~nm}$ & $676 \mathrm{~nm}$ & - & - & 0.32 \\
{$[\ln (P G C)]^{0.5}$} & $\mathrm{dr}_{\mathrm{re}}$ & $441 \mathrm{~nm}$ & $1210 \mathrm{~nm}$ & - & 0.72 \\
{$[\ln (P G C)]^{0.5}$} & $\mathrm{dr}$ & $441 \mathrm{~nm}$ & $1210 \mathrm{~nm}$ & $676 \mathrm{~nm}$ & 0.74 \\
{$[\ln (H)]^{0.5}$} & $1640 \mathrm{~nm}$ & - & - & - & 0.40 \\
{$[\ln (G B M)]^{0.5}$} & $421 \mathrm{~nm}$ & $\mathrm{dr}_{\mathrm{re}}$ & $723 \mathrm{~nm}$ & NDVI & 0.55 \\
{$[\ln (T B M)]^{0.5}$} & $\mathrm{dr}_{\mathrm{re}}$ & $723 \mathrm{~nm}$ & NDVI & - & 0.57 \\
{$[\ln (T B M)]^{0.5}$} & $\mathrm{dr}_{\mathrm{re}}$ & $723 \mathrm{~nm}$ & NDVI & $676 \mathrm{~nm}$ & 0.62 \\
\hline
\end{tabular}

Table 4. Empirical models and performances of the general linear model with disturbance as a class variable $(n=61)$. Class I: less human disturbances in the typical steppe, Class II: more disturbances in the typical steppe, and Class III: desert steppe.

\begin{tabular}{|c|c|c|c|c|c|c|c|c|}
\hline \multirow{4}{*}{ VIs } & \multicolumn{2}{|c|}{$[\ln (P G C)]^{0.5}$} & \multicolumn{2}{|c|}{$[\ln (H)]^{0.5}$} & \multicolumn{2}{|c|}{$[\ln (G B M)]^{0.5}$} & \multicolumn{2}{|c|}{$[\ln (T B M)]^{0.5}$} \\
\hline & Factors & $\mathrm{R}^{2}$ & Factors & $\mathrm{R}^{2}$ & Factors & $\mathrm{R}^{2}$ & Factors & $\mathrm{R}^{2}$ \\
\hline & NDSVI & & NDVI & & NDSVI & & NDSVI & \\
\hline & EVI & 0.73 & & 0.45 & & 0.37 & & 0.48 \\
\hline \multirow{2}{*}{ Reflectance spectra } & $441 \mathrm{~nm}$ & & $1640 \mathrm{~nm}$ & & $421 \mathrm{~nm}$ & & $421 \mathrm{~nm}$ & \\
\hline & $2220 \mathrm{~nm}$ & 0.81 & & 0.49 & $676 \mathrm{~nm}$ & 0.47 & $676 \mathrm{~nm}$ & 0.56 \\
\hline \multirow{3}{*}{ Absorption in red domain } & $\mathrm{D}_{\mathrm{c}}$ & & $\mathrm{D}_{\mathrm{c}}$ & & $\mathrm{D}_{\mathrm{c}}$ & & $\mathrm{D}_{\mathrm{c}}$ & \\
\hline & $\mathrm{dr}_{\mathrm{re}}$ & & $\mathrm{D}_{\mathrm{c}} / \mathrm{D}_{\text {area }}$ & & $\mathrm{dr}_{\mathrm{re}}$ & & $\mathrm{dr}_{\mathrm{re}}$ & \\
\hline & $\mathrm{D}_{\text {area }}$ & 0.65 & & 0.50 & $\mathrm{D}_{\text {area }}$ & 0.59 & $\mathrm{D}_{\text {area }}$ & 0.63 \\
\hline \multirow{4}{*}{ Comprehensive model } & $\mathrm{dr}_{\mathrm{re}}$ & & $\mathrm{D}_{\mathrm{c}}$ & & $421 \mathrm{~nm}$ & & $\mathrm{dr}_{\mathrm{re}}$ & \\
\hline & $441 \mathrm{~nm}$ & & $\mathrm{D}_{\mathrm{c}} / \mathrm{D}_{\text {area }}$ & & $\mathrm{dr}_{\mathrm{re}}$ & & $723 \mathrm{~nm}$ & \\
\hline & $1210 \mathrm{~nm}$ & & & & $723 \mathrm{~nm}$ & & NDVI & \\
\hline & $676 \mathrm{~nm}$ & 0.84 & & 0.50 & NDVI & 0.65 & $676 \mathrm{~nm}$ & 0.70 \\
\hline
\end{tabular}

\section{Discussions}

In this study, VIs, reflectance spectra, continuum removal spectra, and $\mathrm{dr}_{\mathrm{re}}$ based on 61 field measurements across a large area in Inner Mongolia were used to develop empirical models for estimating four key canopy characteristics: $P G C, H, G B M$, and TBM. Our analysis indicated that confidence models could be developed with careful selection of spectral drivers. These models, using different sets of independent drivers, provide us with alternative options (Sections 3.2-3.6). Evaluation of model performances is an essential premise; however, there is still a lack of a generally agreed upon 
set of "optimal" statistical measures for assessing model accuracy [40]. Wide acceptance and the use of a coefficient of determination $\left(\mathrm{R}^{2}\right)$ were utilized in this study.

The conventional biometric approaches for quantifying canopy characteristics in the field are very accurate; however, they are labor-intensive and destructive, resulting in only a small number of communities that can be measured. Remote sensing technology (e.g., the hand-held spectrometer), consequently, becomes an appealing alternative due to its non-destructive, speedy sampling features and coverage of large areas. Mutanga et al. used the field spectrometer successfully to estimate canopy nitrogen, phosphorus, potassium, calcium, and magnesium concentrations in a savanna rangeland based on continuum-removed absorption features and succeeded with a $\mathrm{R}^{2}$ of $0.43-0.80$ [14]. Similarly, Haboudane et al. detected canopy pigment levels (i.e., chlorophyll and carotenes) with a confidence level of $>80 \%$ [41]. In this study, we found the highest confidence in estimating $P G C$ and satisfactory confidence for $G B M$ and $T B M$. The most difficult task remains the prediction of $H$. Nevertheless, it appeared that the hyperspectral spectra in this study contained rich information about canopy characteristics.

Numerous studies have shown that remotely sensed VIs have close correlations with canopy biophysical characteristics and, at the same time, they are less sensitive to other variables such as canopy geometry, soil backgrounds, solar zenith angles, and atmospheric conditions [11,42]. One of our objectives in this study was to examine the feasibility of utilizing these widely used and available indices in the remote sensing community to estimate the canopy biophysical characteristics, which can be scaled up to broader spatial and temporal scales. Here, we confirmed that VIs could be effectively applied for such a purpose (Figure 3, Tables 3 and 4). Surprisingly, LSWI was not selected during the stepwise regression as an important variable. This is likely due to the fact that the region is very dry in the summer months and the surface moisture remains low and similar [43]. Our success is also due to the fact that we did not have the saturation problem of receiving reflectance data from sparse or short vegetation.

Hypothetically, canopy characteristics could be estimated by using proper spectral information. We found that there was a great potential for the use of reflectance spectra in estimating $P G C$, but this use was questionable for $H$. Several authors concluded that the red-edge region was not sensitive to atmospheric or background effects $[14,44]$, regardless of its high correlations with aboveground biomass and leaf area [45]. Moreover, derivative spectra are commonly used to suppress background signals in estimating a range of canopy properties [12], including the chlorophyll absorption feature and the water absorption features [46]. In addition, a study based on a laboratory experiment also showed that the red edge inflection point had a very poor relationship with LAI, particularly when the plant species were pooled together [47]. In this study, the predictive performance of $\mathrm{dr}_{\mathrm{re}}$ was weaker than that of $D_{c}$ (Table 2) when constructing empirical models based on continuum-removed spectra and $\mathrm{dr}_{\mathrm{re}}$ to estimate canopy properties, likely due to dry climate conditions in arid and semi-arid regions [48]. However, when considering all possible spectral information, $\mathrm{dr}_{\mathrm{re}}$ was an essential supplement for detecting $P G C, T B M$, and GBM (Tables 3 and 4). Clearly, the importance of the red-edge region for estimating vegetation biophysical characteristics in arid and semi-arid regions needs further investigations.

The continuum removal approach has been effectively applied to improve the estimation of biomass $[7,14,35,36]$. The amount of green biomass, the cumulative product of photosynthetic abilities and ecosystem respiration, is a function of the absorption feature of electromagnetic energy at specific 
wavelengths in the visible region [14,49]. In this study, we used continuum removal on red absorption features and $\mathrm{dr}_{\mathrm{re}}$ to build regression models for $G B M$ and $T B M$ and found that absorption features in the red region were more closely related to biomass. As suggested by Mutanga et al., the technique of continuum removal on absorption features may also be applied to data acquired by airborne and space-borne imaging spectrometers with high-quality radiometric and geometric calibration of hyperspectral imagery to predict and ultimately map the quality and the quantity of grasslands [14]. Underwood et al. also showed that the processing techniques of continuum removal performed better for classifying one non-native plant of the target species using NASA's hyperspectral imagery AVIRIS (Airborne Visible/Infrared Imaging Spectrometer) [50]. The best empirical models in this study, however, were developed using all of the above spectral information (Table 3), suggesting that a combination of individual spectrum, quantitative indices, and continuum removal approaches is needed. More importantly, selected independent variables for each combination seemed to vary by dependent variable, indicating different sources for our estimations.

A major finding of this study is the importance of including disturbances in predictive models, which were significantly improved from their inclusion (Table 4). Logically, the structural evenness of the sampling community will largely determine vegetation reflectance. Disturbances, depending on their intensity, type and frequency, will increase the heterogeneity of the vegetation. In a highly heterogeneous Mediterranean grassland, Darvishzadeh et al. found that canopy chlorophyll content could be estimated with the highest accuracy $\left(\mathrm{R}^{2}=0.70\right)$ and leaf chlorophyll content could not be estimated with acceptable accuracy, while LAI was estimated with intermediate accuracy $\left(\mathrm{R}^{2}=0.59\right)$ [51]. For estimating $P G C$ in this study, the confidence level was increased to $81 \%$ from $71 \%$ when disturbance was considered in the analysis. Similar degrees of model improvement were also found for $T B M$ and $G B M$ (Tables 3 and 4). Röder et al. pointed out that an estimation of biochemical and biophysical characteristics in heterogeneous grasslands with mixtures of different grass species can be challenging in remote sensing [52]. However, Darvishzadeh et al. also demonstrated that by using hyperspectral measurements with a large number of narrow spectral bands and powerful multivariate regression techniques, biophysical, and, to a lesser extent, biochemical grass characteristics could be retrieved with acceptable accuracy [53].

Finally, limited spectral measurement in a large area with higher spatial heterogeneity may affect the correlation between spectral properties and canopy features as well as the predictive performances of biophysical features based on hyperspectral field spectroscopy. Therefore, when measuring field spectral reflectance, each sampled area should meet a certain scale to be representative of spectral properties of this community type, which can be done by increasing the number of repetitive or homogeneous measurement - a necessity for improving the predictive accuracies based on field spectrometry.

\section{Conclusions}

Previous studies on the utility of hyperspectral field spectroscopy for detecting canopy properties such as LAI, chlorophyll, and foliar nutrients were conducted mainly in laboratory conditions or in small field regions (e.g., plot and stand levels). Here, we conducted intensive field campaigns across the semi-arid region of Inner Mongolia with the goal that the lessons learned from this study can be applied later at broader spatial and temporal scales. We found that: (1) quantitative VIs of NDVI, EVI, 
NDSVI, and LSWI were useful for estimating canopy biophysical features, with NDSVI being the most significant variable; (2) $P G C$ in our region was accurately estimated with spectral reflectance, while $\mathrm{D}_{\mathrm{c}}, \mathrm{D}_{\text {area }}$, and $\mathrm{dr}_{\mathrm{re}}$ were selected for estimating TBM and $G B M$; (3) among the four canopy features, $P G C$ received the highest confidence from all of the models, while $H$ was the most difficult parameter to predict; and (4) the degree of disturbances is a very significant variable in developing empirical models using remote sensing measurements.

\section{Acknowledgments}

This research was jointly supported by the State Key Development Program of Basic Research (2010CB951303), the LCLUC Program of the National Aeronautics and Space Administration (NASA) (NN-H-04-Z-YS-005-N), the R\&D special fund for the public welfare industry (meteorology) project (GYHY201106027), the CHN Program of the NSF, and the IceMe of NUIST. We thank Jianye Xu, $\mathrm{Nan} \mathrm{Lu}$, and Burkhard Wilske from the University of Toledo for their fruitful discussion for this study. We also thank Lisa Delp Taylor, anonymous reviewers and editors for their constructive reviews.

\section{Author Contributions}

Guangsheng Zhou, Feng Zhang, Ranjeet John and Jiquan Chen conceived and designed the research. Feng Zhang, Guangsheng Zhou and Jiquan Chen analyzed the data and wrote the manuscript. Jiquan Chen and Changliang Shao provided data and data acquisition capacity.

\section{Conflicts of Interest}

The authors declare no conflict of interest.

\section{References}

1. Potter, C.S.; Randerson, J.T.; Field, C.B.; Matson, P.A.; Vitousek, P.M.; Mooney, H.A.; Klooster, S.A. Terrestrial ecosystem production: A process model based on global satellite and surface data. Glob. Biogeochem. Cy. 1993, 7, 811-841.

2. Sellers, P.J.; Randall, D.A.; Collatz, G.J.; Berry, J.A.; Field, C.B.; Dazlich, D.A.; Zhang, C.; Collelo, G.D.; Bounoua, L. A revised land surface parameterization (SiB2) for atmospheric GCMs. Part I: Model formulation. J. Clim. 1996, 9, 676-705.

3. Privette, J.L.; Tian, Y.; Roberts, G.; Scholes, R.J.; Wang, Y.; Caylor, K.K.; Frost P.; Mukelabai, M. Vegetation structure characteristics and relationships of Kalahari woodlands and savannas. Glob. Chang. Biol. 2004, 10, 281-291.

4. Hall, F.G.; Townshend, J.R.; Eegman, E.T. Status of remote sensing algorithms for estimation of land-surface state parameters. Remote Sens. Environ. 1995, 51, 138-156.

5. Okin, G.S.; Roberts, D.A.; Murray, B.; Okin, W.J. Practical limits on hyperspectral vegetation discrimination in arid and semiarid environments. Remote Sens. Environ. 2001, 77, 212-225.

6. Goetz, A.F.H. Imaging spectrometry for remote sensing: Vision to reality in 15 Years. Proc. SPIE 1995, 2480, doi:10.1117/12.210867. 
7. Schmidt, K.S.; Skidmore, A.K. Spectral discrimination of vegetation types in a coastal wetland. Remote Sens. Environ. 2003, 85, 92-108.

8. Asner, G.P. Biophysical and biochemical sources of variability in canopy reflectance. Remote Sens. Environ. 1998, 64, 234-253.

9. Knipling, E.B. Physical and physiological basis for the reflectance of visible and near-infrared radiation from vegetation. Remote Sens. Environ. 1970, 1, 155-159.

10. Martin, M.E.; Newman, S.D.; Aber, J.D.; Congalton, R.G. Determining forest species composition using high spectral resolution remote sensing data. Remote Sens. Environ. 1998, 65, 249-254.

11. Mutanga, O.; Skidmore, A.K. Narrow band vegetation indices overcome the saturation problem in biomass estimation. Int. J. Remote Sens. 2004, 25, 3999-4014.

12. Rollin, E.M.; Millton, E.J. Processing of high spectral resolution reflectance data for the retrieval of canopy water content information. Remote Sens. Environ. 1998, 65, 86-92.

13. Asner, G.P.; Wessman, C.A.; Bateson, C.A.; Privette, J.L. Impact of tissue, canopy, and landscape factors on the hyperspectral reflectance variability of arid ecosystems. Remote Sens. Environ. 2000, 74, 69-84.

14. Mutanga, O.; Skidmore, A.K.; Prins, H.H.T. Predicting in situ pasture quality in the Kruger National Park, South Africa, using continuum-removed absorption features. Remote Sens. Environ. 2004, 89, 393-408.

15. Ren, H.; Zhou, G. Estimating senesced biomass of desert steppe in Inner Mongolia using field spectrometric data. Agric. For. Meteorol. 2012, 161, 66-71.

16. Ren, H.; Zhou, G.; Zhang, F.; Zhang, X. Evaluating cellulose absorption index (CAI) for non-photosynthetic biomass estimation in the desert steppe of Inner Mongolia. Chin. Sci. Bull. 2012, 57, doi:10.1007/s11434-012-5016-3.

17. Gausman, H.W. Plant Leaf Optical Properties in Visible and Near Infrared Light; Graduate Studies, Texas Tech University (No. 29); Texas Technical Press: Lubbock, TX, USA, 1985.

18. Carter, G.A. Responses of leaf spectral reflectance to plant stress. Am. J. Bot. 1993, 80, 239-243.

19. Carter, G.A. Ratios of leaf reflectances in narrow wavebands as indicators of plant stress. Int. J. Remote Sens. 1994, 15, 697-703.

20. Roberts, D.A.; Nelson, B.W.; Adams, J.B.; Palmer, F. Spectral changes with leaf aging in Amazon caatinga. Trees 1998, 12, 315-325.

21. Garcia, M.; Ustin, S.L. Detection of interannual vegetation responses to climatic variability using AVIRIS data in a coastal savanna in California. IEEE Trans. Geosci. Remote Sens. 2001, 39, 1480-1490.

22. Smith, K.L.; Steven, M.D.; Colls, J.J. Use of hyperspectral derivative ratios in the red-edge region to identify plant stress responses to gas leaks. Remote Sens. Environ. 2004, 92, 207-217.

23. De Paul Obade, V.; Lal, V.R.; Chen, J. Remote sensing of soil and water quality in agroecosystems. Water Air Soil Pollut. 2013, 224, doi:10.1007/s11270-013-1658-2.

24. John, R.; Chen, J.; Lu, N.; Wilske, B. Land cover /land use change and their ecological consequences. Environ. Res. Lett. 2009, 4, doi:10.1088/1748-9326/4/4/045010.

25. John, R.; Chen, J.; Ou-Yang, Z.-T.; Xiao, J.; Becker, R.; Samanta, A.; Ganguly, S.; Yuan, W.; Batkhishig, O. Vegetation response to extreme climate events on the Mongolian Plateau from 2000 to 2010. Environ. Res. Lett. 2013, 8, doi:10.1088/1748-9326/8/3/035033. 
26. Qi, J.; Chen, J.; Wan, S.; Ai, L. Understanding the coupled natural and human systems in Dryland East Asia. Environ. Res. Lett. 2012, 7, doi:10.1088/1748-9326/7/1/015202.

27. Editoral Committee of Series Resources Maps of Inner Mongolia Autonomous Region (ECSRMIMAR). Explanation of Series Resources Maps of Inner Mongolia Autonomous Region; Science Press: Beijing, China, 1988; pp. 40-128.

28. Savitzky, A.; Golay, M.J.E. Smoothing and differentiation of data by simplified least square procedure. Anal. Chem. 1964, 36, 1627-1638.

29. Rouse, J.W.; Haas, R.H., Jr.; Schell, J.A.; Deering, D.W. Monitoring the Vernal Advancement and Retrogradation (Green Wave Effect) of Natural Vegetation; Progress Report RSC 1978-1; Remote Sensing Center, Texas A\&M University: College Station, TX, USA, 1973.

30. Huete, A.R.; Liu, H.Q.; Batchily, K.; Van Leeuwen, W. A comparison of vegetation indices global set of TM images for EOSMODIS. Remote Sens. Environ. 1997, 59, 440-451.

31. Qi, J.; Marsett, R.; Heilman, P.; Biedenbender, S.; Wallace, O.; Wang, C.; Goodrich, D.; Moran, S.; Weltz, M. Improved rangeland information from satellites for land cover change studies in the Southwest. EOS Trans. AGU 2002, 83, 605-606.

32. Jurgens, C. The modified normalized difference vegetation index (mNDVI) - A new index to determine frost damages in agriculture based on Landsat TM data. Int. J. Remote Sens. 1997, 18, 3583-3594.

33. Xiao, X.; Boles, S.; Liu, J.; Zhuang, D.; Frolking, S.; Li, C.; Salas, W.; Moore, B. Mapping paddy rice agriculture in southern China using multi-temporal MODIS images. Remote Sens. Environ. 2005, 95, 480-492.

34. Filella, I.; Peñuelas, J. The red edge position and shape as indicators of plant chlorophyll content, biomass and hydric. Int. J. Remote Sens. 1994, 15, 1459-1470.

35. Clark, R.N.; Roush, T.L. Reflectance spectroscopy: Quantitative analysis techniques for remote sensing applications. J. Geophys. Res. 1984, 89, 6329-6340.

36. Kokaly, R.F.; Clark, R.N. Spectroscopic determination of leaf biochemistry using optical band-depth analysis of absorption features and stepwise multiple linear regression. Remote Sens. Environ. 1999, 67, 267-287.

37. Curran, P.J.; Dungan J.L.; Peterson, D.L. Estimating the foliar biochemical concentration of leaves with reflectance spectrometry testing the Kokaly and Clark methodologies. Remote Sens. Environ. 2001, 76, 349-359.

38. Darvishzadeh, R.; Atzberger, C.; Skidmore, A.; Schlerf, M. Mapping grassland leaf area index with airborne hyperspectral imagery: A comparison study of statistical approaches and inversion of radiative transfer models. ISPRS J. Photogramm. Remote Sens. 2011, 66, 894-906.

39. Atzberger, C.; Guérif, M.; Baret, F.; Werner, W. Comparative analysis of three chemometric techniques for the spectroradiometric assessment of canopy chlorophyll content in winter wheat. Comput. Electron. Agr. 2010, 73, 165-173.

40. Richter, K.; Atzberger, C.; Hank, T.B.; Mauser, W. Derivation of biophysical variables from earth observation data: Validation and statistical measures. J. Appl. Remote Sens. 2012, 6, doi:10.1117/1.JRS.6.063557. 
41. Haboudane, D.; Miller, J.R.; Tremblay, N.; Zarco-Tejada, P.J.; Dextraze, L. Integrated narrow-band vegetation indices for prediction of crop chlorophyll content for application to precision agriculture. Remote Sens. Environ. 2002, 81, 416-426.

42. Treitz, P.M.; Howarth, P.J. Hyperspectral remote sensing for estimating biophysical parameters of forest ecosystems. Prog. Phys. Geogr. 1999, 23, 359-390.

43. Lu, N.; Chen, S.; Wilske, B.; Sun, G.; Chen, J. Evapotranspiration and soil water relationships in a range of disturbed and undisturbed ecosystems in the semi-arid Inner Mongolia, China. J. Plant Ecol. 2011, 4, 49-60.

44. Clevers, J.; Buker, C. Feasibility of the red edge index for the detection of nitrogen deficiency. In Proceedings of the 5th International Colloquium on Physical Measurements and Signatures in Remote Sensing, Noordwijk, The Netherlands, 14-18 January 1991; ESA SP-319, pp. 165-168.

45. Cho, M.A.; Skidmore, A.K. A new technique for extracting the red edge position from hyperspectral data: The linear extrapolation method. Remote Sens. Environ. 2006, 101, 181-193.

46. Clevers, J.G.P.W.; Kooistra, L.; Schaepman, M.E. Using spectral information from the NIR water absorption features for the retrieval of canopy water content. Int. J. Appl. Earth Obs. 2008, 10, 388-397.

47. Darvishzadeh, R.; Atzberger, C.; Skidmore, A.K.; Abkar, A.A. Leaf Area Index derivation from hyperspectral vegetation indices and the red edge position. Int. J. Remote Sens. 2009, 30, 6199-6218.

48. Ren, H.; Zhou, G.; Zhang, X. Estimation of green aboveground biomass of desert steppe in Inner Mongolia based on red-edge reflectance curve area method. Biosyst. Eng. 2011, 109, 385-395.

49. Ponzoni, F.J.; Goncalves, J.L. Spectral features associated with nitrogen, phosphorous, and potassium deficiencies in Eucalyptus saligna seedling leaves. Int. J. Remote Sens. 1999, 20, 2249-2264.

50. Underwood, E.; Ustin, S.; DiPietro, D. Mapping nonnative plants using hyper spectral imagery. Remote Sens. Environ. 2003, 86, 150-161.

51. Darvishzadeh, R.; Skidmore, A.; Schlerf, M.; Atzberger, C. Inversion of a radiative transfer model for estimating vegetation LAI and chlorophyll in a heterogeneous grassland. Remote Sens. Environ. 2008, 112, 2592-2604.

52. Röder, A.; Kuemmerle, T.; Hill, J.; Papanastasis, V.P.; Tsiourlis, G.M. Adaptation of a grazing gradient concept to heterogeneous Mediterranean rangelands using cost surface modelling. Ecol. Model. 2007, 204, 387-398.

53. Darvishzadeh, R.; Skidmore, A.; Schlerf, M.; Atzberger, C.; Cho, M.A. LAI and chlorophyll estimation for a heterogeneous grassland using hyperspectral measurements. ISPRS J. Photogramm. Remote Sens. 2008, 63, 409-426.

(C) 2014 by the authors; licensee MDPI, Basel, Switzerland. This article is an open access article distributed under the terms and conditions of the Creative Commons Attribution license (http://creativecommons.org/licenses/by/3.0/). 